\title{
DIABETIC NEPHROPATHY; PROTEIN TO CREATININE RATIO AS A COST EFFECTIVE DIAGNOSTIC TOOL FOR DETECTION
}

1. Department of Radiology, Allied Hospital Faisalabad.

2. Department of Radiology, Allied Hospital Faisalabad.

3. Department of Radiology,

Allied Hospital Faisalabad.

Correspondence Address: Dr. Hassan Bukhari Department of Radiology,

Allied Hospital Faisalabad.

drhassanbukhari@hotmail.com

Article received on: 10/12/2015

Accepted for publication: 08/01/2016

Received after proof reading: $10 / 03 / 2016$

\section{Dr. Hassan Bukhari', Dr. Asim Shaukat ${ }^{2}$, Dr. Amir Hayyat Mahes ${ }^{3}$}

\begin{abstract}
Objectives: To determine diagnostic accuracy of spot urine Protein to creatinine ratio for detection of diabetic nephropathy taking 24-hour urinary protein as gold standard. Study Design: cross sectional. Settings: Medical and Radiology department of Allied hospital Faisalabad. Duration: 12-12-2013 to 12-06-2014. Sample size: 134. Material \& Methods: It was a cross-sectional study done in Medical Unit I, Allied Hospital Faisalabad. 134 patients with suspicion of diabetic nephropathy were included. 24-hour urine sample collected by instructing patients to begin collection immediately after completion of first voiding in morning and to collect all urine into same container having $5 \mathrm{~mL}$ of $10 \%$ thymol in iso-propanol as a preservative for 24-hours. This was thoroughly mixed, $2 \mathrm{~mL}$ was taken for evaluation of proteins. P.C ratio was calculated by dividing Urinary Protein concentration by Urinary Creatinine concentration. Results: The mean age of patients was noted as $55.11 \pm 6.79$ years. There were $62.7 \%$ male and $37.3 \%$ female patients. Mean PC ratio of the patients was noted as $0.21 \pm 0.07$. Sensitivity of PC ratio was noted as $95.2 \%$, whereas specificity was $76.5 \%$, PPV $86.8 \%$, NPV $90.7 \%$ with diagnostic accuracy of $88.1 \%$. Conclusion: The study results showed that PC ratio is sensitive enough to diagnose diabetic nephropathy instead of 24-hour urinary protein.
\end{abstract}

Key words: $\quad$ Diabetic Nephropathy, PC Ratio, Albuminuria.

Article Citation: Bukhari H, Shaukat A, Mahes AH. Diabetic nephropathy; protein to creatinine ratio as a cost effective diagnostic tool for detection. Professional Med $\mathrm{J}$ 2016;23(3):302-306. DOI: 10.17957/TPMJ/16.3184

\section{INTRODUCTION}

Diabetic neuropathy (DN),a clinical syndrome, regarded as tenacious albuminuria $(>300 \mathrm{mg} / \mathrm{d}$ or $>200 \mu \mathrm{g} / \mathrm{min}$ ) which is established on at least 2 times,3-6 months apart, raised arterial blood pressure and reformist decrease in glomerular filtration rate(GFR). ${ }^{1,2}$

According to latest literature, whole occurrence of DN was considered as $42.5 \% .^{3}$ Generally, DN is considered after a mundane analysis of urine and screening of micro albuminuria in diabetes setting. ${ }^{4}$

It is controversial that GFR calculations, which are creatinine-based, is the most delicate and sensitive method for assessment of early decline in renal function in patients with type 2 diabetes who are having mild to moderate CKD. ${ }^{5}$

A gold standard for quantitative evaluation of proteinuria is 24-hour urinary protein (UP).It has sensitivity and specificity of $100 \%$ and $90 \%$ respectively. This method is, however, cumbrous and inconvenient because it is challenging to collect accurately complete 24 hour urine samples particularly in out-patient set up. A substitute method, for quantitative evaluation of proteinuria, is protein-to-creatinine ratio (PCR) measurement which is done on untimed spot urine specimen. It provides a more suitable and convenient method to measure the protein excretion. Even though there is reasonable co-relation between PCR and UP yet the settlement between these two measuring techniques should be evaluated when considering one for replacement of other. ${ }^{6}$

According to a study, spot urine P:C ratio for sensitivity and specificity is $93.55 \%$ and $72.73 \%$ amongst the patients of type II diabetes who are taking 24-hour urinary protein as gold standard. ${ }^{7}$

The objective of my study is that spot urine P.C ratio is not in local practice. If accurateness of spot 
urine is found, results of the study will definitely will be supportive for quick and early detection of diabetic neuropathy as extended time is taken by 24-hour urine protein.

\section{MATERIAL AND METHODS}

Cross-sectional study conducted in Medical Unit I, Department of Medicine and Radiology, Allied Hospital, Faisalabad. Mandatory ultrasound was performed by the consultant Radiologist using LOGIC 5 Doppler ultrasound machine for evaluation of renal status. After taking approval from Hospital Ethical Committee, 134 patients who fulfill the inclusion and exclusion criteria were enrolled in the study from OPD of Allied Hospital, Faisalabad. Informed consent of patients was obtained. All basic demographic information of each patient (name, age, sex, address and contact) was noted.

\section{Inclusion criteria}

- Age: 45-70years

- Gender: both gender (male and female)

- Suspected case of Diabetic nephropathy:

As mentioned in operational definition

\section{Exclusion criteria}

- Pregnant females

- $\operatorname{HTN}(B P \geq 140 / 90 \mathrm{mmHg})$

- poorly controlled DM (BSR>200mg/dl)

- chronic renal failure before diabetes (Serum creatinine $>1.2 \mathrm{mg} / \mathrm{dl}$ )

- Patients with UTI (on laboratory examination)

- Glomerular nephritis due to other systemic conditions as mentioned above.

24-hour urine sample was collected by instructing patients to begin collection immediately after completion of first voiding in morning and to collect all urine into same container having $5 \mathrm{~mL}$ of $10 \%$ thymol in iso-propanol as a preservative for 24 hours, including final void at completion of 24 hour period in the pathology laboratory of the hospital.

The collected data was analysed statistically by using SPSS version 16 .

\section{RESULTS}

Total 134 cases were enrolled in this study from OPD of Allied Hospital, Faisalabad. The mean age of patients was noted as $55.11 \pm 6.79$ years with minimum and maximum ages of 45 and 70 years respectively. Table-I.

\begin{tabular}{|c|c|c|} 
& $\mathbf{n}$ & 134 \\
\hline \multirow{3}{*}{ Age (Years) } & Mean & 55.11 \\
\cline { 2 - 3 } & SD & 6.79 \\
\hline & Minimum & 45 \\
\hline & Maximum & 70 \\
\hline
\end{tabular}

Table-l. Descriptive statistics of age (years) of patients

Out of 134 patients in this study, 84 (62.7\%) patients were males whereas $50(37.3 \%)$ patients were females. Figure-1

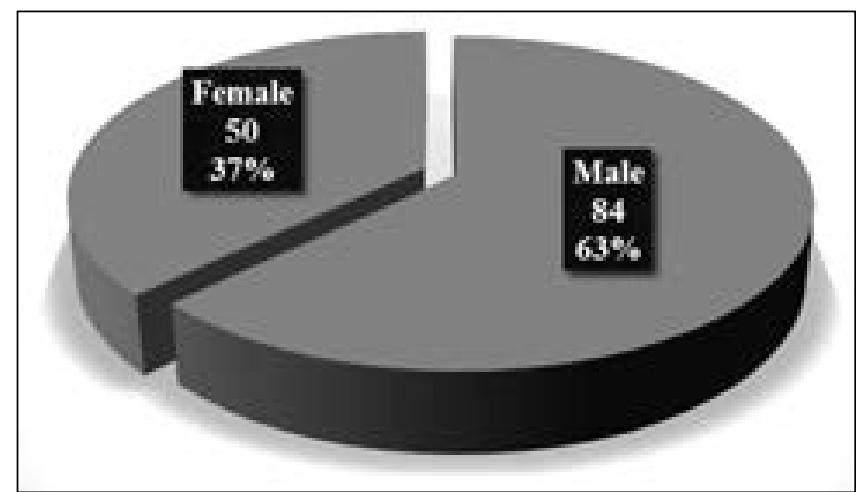

Figure-1. Distribution about Gender of the Patients

The study results showed that the mean $\mathrm{PC}$ ratio of the patients was noted as $0.21 \pm 0.07$ with minimum and maximum ratios of $0.10 \& 0.33$ respectively. Table-II.

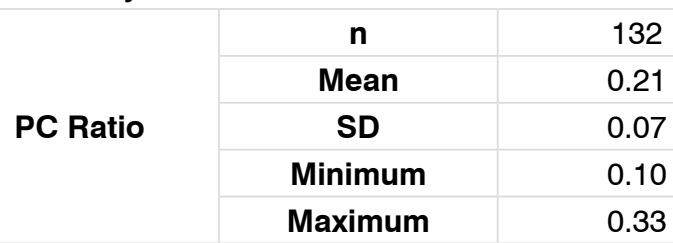

Table-II. Descriptive statistics of PC ratio of the patients

In this study most of 91 (67.9\%) patients had positive PC ratio and $43(32.1 \%)$ had negative PC ratio. Table-III.

\begin{tabular}{|c|c|c|c|}
\hline & & Frequency & Percent \\
\hline \multirow{3}{*}{ PC Ratio } & Positive & 91 & $67.9 \%$ \\
\cline { 2 - 4 } & Negative & 43 & $32.1 \%$ \\
\hline & Total & $\mathbf{1 3 4}$ & $\mathbf{1 0 0 . 0 \%}$ \\
\hline
\end{tabular}

Table-III. Distribution of PC ratio of patients 
The mean protein level of the patients was observed as $345.75 \pm 112.49 \mathrm{mg} / \mathrm{l}$ with minimum and maximum values of $136 \mathrm{mg} / \mathrm{l}$ and $500 \mathrm{mg} / \mathrm{l}$ respectively. Table-IV.

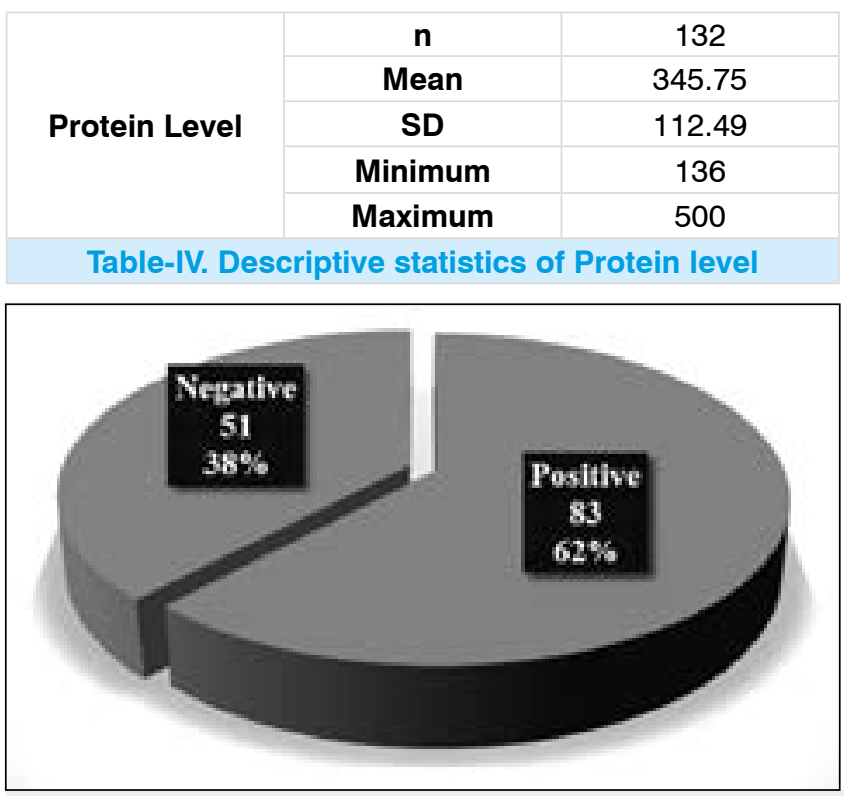

Figure-2. Distribution about protein level of patients

The protein level was positive in 83 (61.9\%) patients and was negative in $51(38.1 \%)$ patients. Figure-2

Thus $2 \times 2$ table was generated to measure the diagnostic accuracy of P.C ratio taking 24 hours urinary protein as gold standard. The sensitivity of P.C ratio was calculated as $95.2 \%$, whereas the specificity was found as $76.5 \%$. The PPV was calculated as $86.8 \%$ and NPV was calculated as $90.7 \%$. The overall diagnostic accuracy of P.C ratio was $88.1 \%$. Table-V.

\begin{tabular}{|c|c|c|c|c|}
\hline & \multicolumn{2}{|c|}{ Protein Level } & \multirow{2}{*}{ Total } \\
\hline & & Positive & Negative & \\
\hline \multirow{2}{*}{ PC Ratio } & Positive & 79 & 12 & 91 \\
\hline & Negative & 4 & 39 & 43 \\
\hline \multicolumn{2}{|c|}{ Total } & 83 & 51 & 134 \\
\hline \multicolumn{5}{|c|}{$\begin{array}{c}\text { Table-V. Comparison of PC ratio with } 24 \text { hours urinary } \\
\text { Protein }\end{array}$} \\
\hline
\end{tabular}

\section{Sensitivity \\ Specificity \\ Positive Predictive Value \\ Negative Predictive Value Diagnostic Accuracy}

$95.2 \%$

$76.5 \%$

\section{DISCUSSION}

Proteinuria quantification is significant for observing disease advancement and response to therapies in patients with numerous types of nephritis like diabetic nephropathy, owing to hypertension and unknown etiology. According to the guidelines for the management of kidney disease, one of the remission criteria for kidney disease diagnosis is 24-hour urine total protein $<0.5 \mathrm{~g} /$ day.

Threshold or clinically significant value of Proteinuria of $>1 \mathrm{~g} /$ day is considered for renal biopsy. Further, proteinuria, in nephrotic range is severe i.e. $>3.5 \mathrm{~g} / \mathrm{day}^{8}{ }^{8} \mathrm{~A}$ worldwide elevation in urinary protein excretion in diagnosis ,detection and people management who are considered to be at high risk of developing renal diseases regular check-up in such individuals. ${ }^{9}$

Since renal involvement is reversible at initial stage that's why it is important to detect renal contribution. Further, the disease progressin can be checked. Early detection diminishes both the treatment cost and also mortality. ${ }^{10}$

The current study showed that patients mean age was $55.17 \%$ males although most patients were males. Males were $62.7 \%$ and women were $55.112 .7 \%$ as reinforced bt Yadav et al. study. Rendering the results of Yadav study, amongst 144 subjects, 103 were maes and females were $25 .{ }^{11}$

Jayasekara JMKB et al study also showed more male patients. in their study 28 were males and 20 were females. (8) Monika Pathania et al., enrolled 179 patients with DM participated in the study. Out of 179 participant's, 103 (57.54\%) were male and $76(42.46 \%)$ were female. Participants' age ranged from 23 to 88 years, with an average of $56.42 \pm 12.2$ years. $^{10}$

Sensitivity of P.C ratio taking protein level as gold standard was renowned as $95.2 \%$ but specificity was found $76.5 \%$, PPV values were $86.8 \%$, of NPV was $90.7 \%$ having accuracy of $88.1 \%$.Our study was reinforced by other authors like Jung-Hwa 
Park., et al decided that Random urine P:c ratio is consistent marker of significant proteinuria in preeclampsia and possibly be better at providing earlier diagnostic information as compared to 24-hour urine protein excretion and having more correctness as compared to urinary dipstick test(12).Some researchers projected that more accurate and rapid diagnostic test having the ability of predicting 24-hour urine protein excretion would be highly important, by using random urine P.C ratio to simplify prompt decision making by clinicians. ${ }^{13,14}$

Usefulness of random urine P.C ratio have been established already by numerous scientists, as well as some that have accessible indication of good association with adequate sensitivity in forecasting significant proteinuria founded on urine collected at different time periods. ${ }^{15-17}$ Yadav BK et al showed a positive association between the random urine P.C ratio and 24-hour urinary protein in type 2 diabetes mellitus patients.

Ruggenenti $P$ et al showed that P.C ratio forecast the rate of failure even more accurately than 24hour urinary protein excretion, which proposes that the random urine P.C ratio is more precise catalog of kidney traffic of plasma proteins compared to 24-hour urinary total proteins. ${ }^{18}$ Seyed-Ali and Navin Jaipaul found that the random urine P.C ratio is a consistent and practical way of assessing and following proteinuria, but its precision and accuracy may be affected by the level of patient physical activity. ${ }^{19}$

Jiunn-Min Wang et al concluded that $\mathrm{P}: \mathrm{C}$ ratio or albumin to Creatinine ratio, which was acquired by dipstick, can be used to screen the potential danger of renal diseases in hypertensive, outpatient and diabetic patients. At the ideal cutoff point of 0.15 , the investigative presentation was high with sensitivity and specificity of 96.65 and $74.4 \%$ respectively. ${ }^{20}$ The higher value found for sensitivity compared with specificity would propose that the ratio test might be more cherished as a rule out test suggested by BK Yadav et al. ${ }^{55}$ Nahid Shahbazian and Farzaneh Hosseini-Asl concluded that a random urine P.C ratio forecasts the amount of 24-hour urine protein excretion with a highly accuracy. ${ }^{21}$

Torng. Setal., in their study of urine protein to creatinine ratio as a prognosticator of 24-h urine protein excretion in renal transplant patients stated that urine $\mathrm{P} / \mathrm{C}$ ratio is a useful and suitable with high sensitivity (74.4-90\%) and specificity values (93-98\%) for approximating proteinuria from 0.5 to $2 \mathrm{~g} /$ day. ${ }^{22}$ Few authors have made reference to the use of the protein, creatinine ratio for the purposes of presiding out proteinuria; however, Dyson et al. illustrated attention to this usage and to the fact that it can decrease the need on a test procedure (i.e., 24-hour urinary protein) that is both unreliable and costly. ${ }^{23}$

\section{CONCLUSION}

The study results showed that $P C$ ratio was sensitive enough to diagnose diabetic nephropathy instead of 24-hour urinary protein which time and cost consuming. Now in future we can recommend and rely upon the use of spot urine PC ratio for diagnosis of diabetic nephropathy instead of waiting for 24-hours urinary protein.

Copyright @ 08 Jan, 2016.

\section{REFERENCES}

1. Chiarelli F, Gaspari S, Marcovecchio M. Role of growth factors in diabetic kidney disease. Hormone and metabolic research. 2009;41(08):585-93.

2. Rask-Madsen C, King GL. Kidney complications: factors that protect the diabetic vasculature. Nature medicine. 2010;16(1):40-1.

3. Alrawahi AH, Rizvi SG, Al-Riyami D, Al-Anqoodi Z. Prevalence and risk factors of diabetic nephropathy in omani type 2 diabetics in Al-dakhiliyah region. Oman Med J. 2012 May;27(3):212-6.

4. Jayakumar R. Risk factors in diabetic nephropathy. International Journal of Diabetes in Developing Countries. 2012;32(1):1-3.

5. Iliadis $F$, Didangelos $T$, Ntemka A, Makedou A, Moralidis E, Gotzamani-Psarakou A, et al. Glomerular filtration rate estimation in patients with type 2 diabetes: creatinine-or cystatin C-based equations? Diabetologia. 2011;54(12):2987-94.

6. Wahbeh AM, Ewais MH, Elsharif M. Comparison of 24- 
hour urinary protein and protein-to-creatinine ratio in the assessment of proteinuria. Saudi Journal of Kidney Diseases and Transplantation. 2009;20(3):443.

7. Biradar SB, Kallaganad GS, Rangappa M, Kashinakunti SV, Retnakaran R. Correlation of spot urine proteincreatinine ratio with 24-hour urinary protein in type 2 diabetes mellitus patients: A cross sectional study. $\mathrm{J}$ Res Med Sci. 2011 May;16(5):634-9.

8. JMKB J, Gunaratne M, Amunugama K. Estimation of 24 Hour Protein in CKD Patients by analyzing the Protein/Creatinine Ratio of Four Spot Urine Samples. Scientific and Research Publications,. 2013;3(3).

9. Hogg RJ, Furth S, Lemley KV, Portman R, Schwartz GJ, Coresh J, et al. National Kidney Foundation's Kidney Disease Outcomes Quality Initiative clinical practice guidelines for chronic kidney disease in children and adolescents: evaluation, classification, and stratification. Pediatrics. 2003;111(6):1416-21.

10. Pathania M, Rathaur VK, Yadav N, Jayara A. Quantitative Micro-albuminuria Assessment from 'Random Voided Urinary Albumin: Creatinine Ratio'Versus '24 hours Urinary Albumin Concentration'for Screening of Diabetic Nephropathy. 2013.

11. Yadav B, Adhikari S, Gyawali P, Shrestha R, Poudel $B$, Khanal $M$. Use of protein: creatinine ratio in a random spot urine sample for predicting significant proteinuria in diabetes mellitus. Nepal Med Coll $\mathrm{J}$. 2010;12(2):100-5.

12. Park J-H, Chung D, Cho H-Y, Kim Y-H, Son G-H, Park Y-W, et al. Random urine protein/creatinine ratio readily predicts proteinuria in preeclampsia. Obstetrics \& gynecology science. 2013;56(1):8-14.

13. Roudsari FV, Ayati S, Ayatollahi H, Shakeri M. Protein/creatinine ratio on random urine samples for prediction of proteinuria in preeclampsia. Hypertension in Pregnancy. 2012;31(2):240-2.

14. Sethuram R, Kiran TU, Weerakkody AA. Is the urine spot protein/creatinine ratio a valid diagnostic test for pre-eclampsia? Journal of Obstetrics \& Gynaecology. 2011;31(2):128-30.
15. Silpraset S, Praloprakarn C, Manussirivithyaya S, Wiriyasirivaj B. A six-hour urinary protein-creatinine ratio for predicting significant proteinuria in preeclampsia. Thai J Obstet Gynecol. 2009;17:30-6.

16. Saikul S, Wiriyasirivaj B, Charoenchinont P. First 4-hour urinary protein-creatinine ratio for diagnosis of significant proteinuria in preeclampsia. $J$ Med Assoc Thai. 2006;89(Suppl 4):S42-S6.

17. Wiwanitkit V. Periodic urinary protein creatinine ratio for predicting significant proteinuria in preeclampsia in different alternatives: time effectiveness analysis. Archives of gynecology and obstetrics. 2010;281(3):5713.

18. Ruggenenti P, Gaspari F, Perna A, Remuzzi G. Cross sectional longitudinal study of spot morning urine protein: creatinine ratio, 24 hour urine protein excretion rate, glomerular filtration rate, and end stage renal failure in chronic renal disease in patients without diabetes. Bmj. 1998;316(7130):504-9.

19. Sadjadi S-A, Jaipaul N. Correlation of random urine protein creatinine (PC) ratio with 24-hour urine protein and PC ratio, based on physical activity: a pilot study. Therapeutics and clinical risk management. 2010;6:351.

20. Wang J-M, Lin C-Y, Tsai F-A, Chen J-Y, Koa Y-C. Test dipstick for determination of urinary protein, creatinine and protein/creatinine ratio. J Biomed Lab Sci. 2009;21(1):23.

21. Shahbazian N, Hosseini-Asl F. A comparison of spot urine protein-creatinine ratio with 24-hour urine protein excretion in women with preeclampsia. Iran J Kidney Dis. 2008;2(3):127-31.

22. Torng S, Rigatto C, Rush DN, Nickerson P, Jeffery JR. The urine protein to creatinine ratio $(\mathrm{P} / \mathrm{C})$ as a predictor of 24-hour urine protein excretion in renal transplant patients. Transplantation. 2001;72(8):1453-6.

23. Dyson E, Will E, Davison A, O'Malley A, Shepherd H, Jones $R$. Use of the urinary protein creatinine index to assess proteinuria in renal transplant patients. Nephrology Dialysis Transplantation. 1992;7(5):450-2.

\section{AUTHORSHIP AND CONTRIBUTION DECLARATION}

\begin{tabular}{|c|l|l|l|}
\hline Sr. \# & \multicolumn{1}{|c|}{ Author-s Full Name } & \multicolumn{1}{|c|}{ Contribution to the paper } & Author=s Signature \\
\hline 1 & Dr. Hassan Bukhari & 1 st Author \\
2 & Dr. Asim Shaukat & 2nd Author \\
3 & Dr. Amir Hayyat Mahes & 3rd Author & \\
\hline
\end{tabular}

